\title{
New Challenges
}

\section{Dear Readers,}

The importance of acoustics in automotive development and research continues to grow. At the same time, the requirements are becoming increasingly complex. Customers make ever higher demands for the quality of their vehicles, with acoustics playing an important role, and in many countries around the world the legal requirements for vehicles regarding noise and, above all, emissions have become and will continue to become tougher than ever. As such, today's engineers find themselves confronted with a significantly higher number of possible drive architectures, which push the complexity of the task at hand to an unprecedented level. In short: We face a complex mix of factors that present countless challenges, both old and new, on the path towards optimal NVH performance.

To this end, together with our cooperation partner Autoneum we have set out a number of the most important issues in this booklet, in order to present interesting solutions, tools and approaches. Some of these are technical updates to lectures from the last Automotive Acoustics Conferences. However, other solutions are new and we hope that these will prompt new ideas, as well as potentially becoming topics for discussion at the next Automotive Acoustics Conference in 2017. In the future, this booklet will be published by ATZ and Autoneum regularly between our biennial conferences. On the one hand, this will help to bridge the time gap between events, while, on the other, also serving as a platform for technical articles to supplement and expand upon discussions at the Automotive Acoustics Conferences.
We would be delighted if you could make a note of the dates for the next conference: It is due to take place on July 11 and 12, 2017 in Zurich (Switzerland).

I hope that you enjoy reading our first ATZextra Automotive Acoustics booklet.

Yours sincerely,

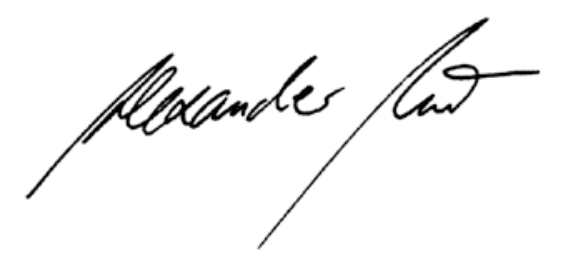

Dr. Alexander Heintzel

Editor in Chief

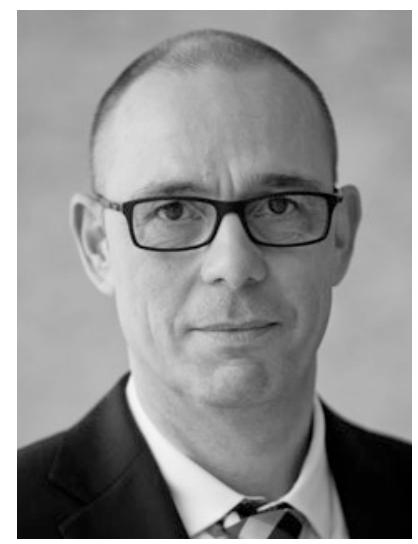

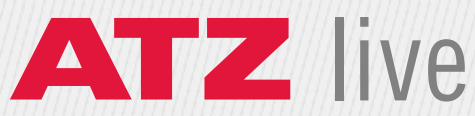

4th International ATZ Conference

\section{Automotive Acoustics Conference}

\section{July 11-12, 2017 \\ Zurich I Switzerland}

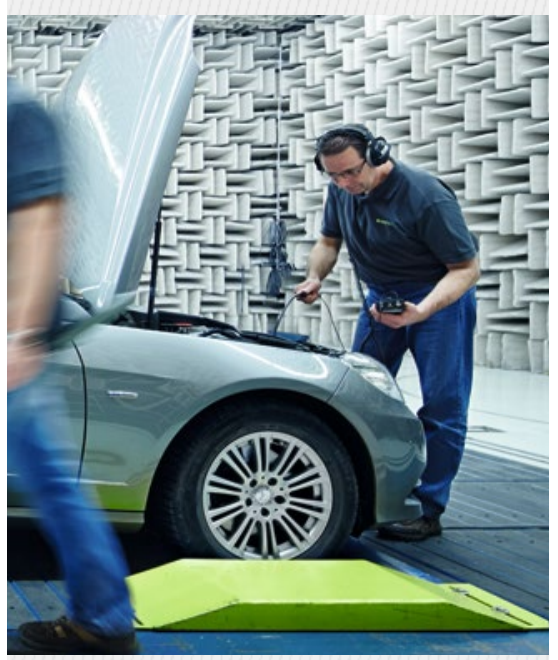

MAIN SUBJECT AREAS

LIGHTWEIGHT STRUCTURES AND NVH Design \& Material Technologies

NVH OF HEVs \& BEVs

Challenges and E-Sources

Characterization

VEHICLE EXTERIOR NOISE

Legislation, NVH Solutions,

Tools and Diagnostic Methods

SCIENTIFIC DIRECTOR

Dr. Davide Caprioli, Autoneum
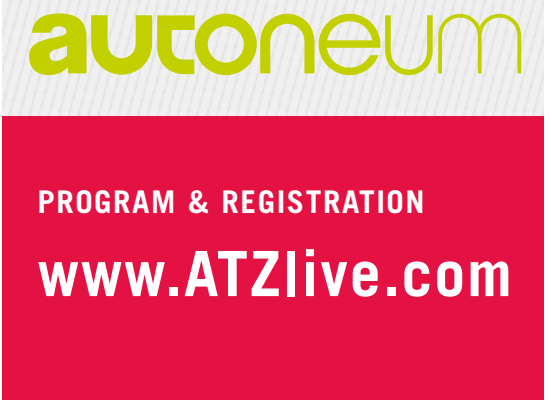